\title{
Considerações Epistemológicas Sobre o Inatismo dos Direitos Humanos Universais: Aportes para a dignidade humana
}

\section{Leilane Serratine Grubba'}

\section{Resumo}

Este artigo tem por objeto a epistemologia empirista de John Locke. Nesse sentido, objetivou investigar a crítica de Locke ao inatismo das ideias e princípios, no intuito de averiguar a noção inatista da universalidade dos direitos humanos. 0 texto problematizou epistemologicamente a garantia universal dos direitos humanos e a sua eficácia concreta no desenvolvimento da vida digna, material e imaterialmente. Para tanto, em primeiro lugar foi apresentada a teoria empirista de John Locke. Sequencialmente, foi analisada a crítica de Locke à noção racionalista do inatismo do conhecimento e das ideias. Por fim, foi apresentada a crítica desse pensador ao inatismo da concepção da universalidade dos direitos humanos, em contraposição à noção da vida digna material e imaterial. Considerou-se que os direitos humanos devem ser entendidos contextualmente, de modo a garantir a dignidade imanente e à satisfação das necessidades.

Palavras-chave: Epistemologia. Conhecimento jurídico. Metodologia jurídica. Direitos humanos. John Locke.

${ }^{1}$ Doutoranda em Direito pelo Programa de Pós-Graduação em Direito da Universidade Federal de Santa Catarina. É mestre em direito (PPGD/UFSC) e bolsista de doutorado CNPq. Professora substituta de Criminologia e Direito Penal DIR/UFSC. 1sgrubba@hotmail.com 


\title{
EPISTEMOLOGICAL CONSIDERATIONS ON INNATENESS OF UNIVERSAL HUMAN RIGHTS: contributions to human dignity
}

\begin{abstract}
This article focuses on the empiricist epistemology of John Locke. In this sense, we investigate the Locke's criticism on innateness philosophy, in order to examine the innate sense of the universality of human rights. In this article we epistemologically problematized the universal human rights and their actual effectiveness in the development of decent life, materially and immaterially. Therefore, first, was presented the empiricist theory of John Locke. Sequentially, we analyzed the criticism of Locke the rationalist notion on the theory of innateness knowledge and ideas. Finally, we have shown the critical thought of innateness conception on the universality of human rights, as opposed to the notion of life worthy materially and immaterially. We considered that human rights must be understood contextually in order to ensure the inherent dignity and satisfaction of needs.
\end{abstract}

Keywords: Epistemology. Legal Knowledge. Legal Methodology. Human Rights. John Locke.

\section{Sumário}

1. Introdução. 2. Noções Preliminares da Epistemologia de John Locke. 3. A Crítica Lockiana ao Inatismo: a Questão dos Princípios Universais. 4. Direitos Humanos Universais e Inatos: Aportes Para a Defesa da Satisfação das Necessidades de uma Vida Digna. 5. Considerações Finais. Referências 


\section{INTRODUÇÃO}

A abordagem epistemológica dos direitos humanos pressupõe uma visão prévia do ser humano e uma demarcação do objeto de estudo. $\mathrm{O}$ humano é um ser contextual na medida em que ele trava relações consigo, com os demais e com o ambiente no qual está inserido. Isso significa percebê-lo como parte integrante do meio ambiente no qual está inserido, como um ser contextual, temporal e geográfico. Nesse sentido, cada ser humano detém uma identidade própria e, por consequência dela, diferenças para com os demais. Em suma, todos são contextuais porque constroem essa identidade individualmente, em razão da genética, dos valores, da cultura, do modo de produção e consumo de sua localidade geográfica, do tempo no qual nasceu e se desenvolveu, do grau de escolaridade, etc.

É justamente a partir dessa identidade que cada ser humano se relaciona com os fenômenos do mundo, consigo, com os outros humanos, com a natureza, assim como com as dimensões da vida em sociedade (economia, política, etc.). Daí porque cada ser humano, ou cada grupo ou cultura possui valores e princípios próprios, os quais são aprendidos e ensinados e visam ao alcance e manutenção da vida em dignidade, não havendo princípios universalmente inatos.

Nesse sentido, este artigo, que tem por objeto a epistemologia empirista de John Locke, objetivou investigar, epistemologicamente, a crítica de Locke à Filosofia racionalista do inatismo das ideias e princípios, no intuito de averiguar a noção inatista da universalidade (ou universalização) dos direitos humanos. Por meio de uma metodologia dedutiva, o artigo problematizou epistemologicamente a garantia universal dos direitos humanos e a sua eficácia concreta no desenvolvimento da vida digna, material e imaterialmente. 
Diante disso, em primeiro lugar, apresentamos a teoria empirista de John Locke, para a qual todo o conhecimento advém da experiência sensível, por meio da percepção, que é sempre o início do conhecimento. Sequencialmente, analisamos a crítica de Locke à noção racionalista do inatismo do conhecimento e das ideias. Se, para Locke, todo o conhecimento advém da experiência, não existe o conhecimento racional $a$ priori ou o conhecimento de princípios inatos, mas somente a percepção da experiência para a formação do conhecimento. Por fim, apresentamos a crítica desse pensador ao inatismo para pensarmos a concepção da universalidade dos direitos humanos, em contraposição à noção da vida digna material e imaterial. Consideramos que os direitos humanos devem ser entendidos contextualmente, de modo a garantir a dignidade imanente e a satisfação das necessidades.

\section{NOÇÕES PRELIMINARES DA EPISTEMOLOGIA DE JOHN LOCKE}

Locke é considerado um representante do modelo empirista do conhecimento. De fato, a formação médica de Locke o influenciou na aderência ao empirismo, segundo Andery, Micheletto e Sério (2007, p. 221-222). Além disso, o pensamento filosófico de Locke foi marcado pela preocupação com a constituição do processo de produção do conhecimento humano. Para os autores supramencionados, essa preocupação se vinculava às ideias políticas de Locke e a sua tentativa de desvendar, de modo objetivo, os processos da vida pública. Daí porque, sendo liberalista e defensor da monarquia parlamentarista, o pensador criticou as ideias religiosas que justificavam o absolutismo monárquico.

John Locke (1621-1704) considerou o entendimento como a faculdade mais nobre da alma. Ele buscou compreender o que é o entendimento e percebeu que todo o conhecimento humano advém da experiência. Sua obra Ensaio acerca do entendimento humano, nesse sentido, 
sistematizou a teoria empirista do conhecimento, isto é, a teoria segundo a qual a experiência sensível é o fundamento do conhecimento (Locke, 1999, p. 25).

Tendo considerado a sua tese sobre o conhecimento tão sujeita ao erro como qualquer outra, Locke (1999, p. 25) afirmou que o entendimento é o que diferencia o homem dos demais seres sensíveis, situando-o acima dos animais em sua superioridade e lhe dá vantagem e domínio. É justamente por tal nobreza que devemos, segundo o autor, investigar o entendimento (p. 29).

Visando à compreensão do conhecimento, a primeira investigação consiste em verificar, segundo Locke (1999, p. 37), como as ideias ${ }^{2}$ aparecem na mente. Esse pensador indagou a extensão e o limite do entendimento humano e criticou a doutrina das ideias inatas, conforme veremos mais detalhadamente, próprias do racionalismo, ou seja, de que o ser humano nasce com conhecimento, independentemente das suas experiências. Para ele, nem todas as pessoas nascem com os mesmos conhecimentos, assim como, por exemplo, nem todos os humanos conhecem os princípios da identidade e da contradição lógica. Nesse sentido, os princípios inatos não são universais e, por isso mesmo, o inatismo é uma falsa doutrina. Se Locke não considera as ideias inatas, o que devemos considerar ideias em seu pensamento? A ideia é o objeto do pensamento, visto que "[...] todo homem tem consciência de que pensa e, que quando está pensando sua mente se ocupa de ideias" (p. 57).

\footnotetext{
${ }^{2}$ A ideia, no texto de Locke, significa "[...] qualquer coisa que consiste no objeto do entendimento quando o homem pensa, usei-o para expressar qualquer coisa que pode ser entendida como um fantasma, noção, espécie, ou tudo o que pode ser empregado pela mente pensante; e não pude evitar seu uso freqüente.” Além disso, Locke afirma a existência de qualidades primárias e de qualidades secundárias de um objeto externo. As qualidades primárias são inseparáveis dos corpos dos objetos, como a solidez, a extensão, etc. As qualidades secundárias não estariam nos objetos, segundo Locke, se não fosse para produzir sensações nos sujeitos, como os sons e gostos (Locke, 1999, p. 32-33).
} 
As ideias sempre derivam da sensação ou da reflexão. Considerando a mente como um papel em branco, ela será suprida com a experiência. Nesse sentido, todo o conhecimento humano funda-se na experiência, não havendo, para o autor, conhecimento inato ou apriorístico. A experiência pode ser empregada tanto nos objetos sensíveis externos quanto nas operações internas de nossas mentes, que são por nós percebidas e refletidas. Todas as ideias humanas fluem dessas duas fontes do conhecimento (1999, p. 57). O objeto do conhecimento, segundo Locke, é a primeira fonte de ideias no seguinte sentido:

Primeiro, nossos sentidos, familiarizados com os objetos sensíveis particulares, levam para a mente várias e distintas percepções das coisas, segundo os vários meios pelos quais aqueles objetos os impressionaram. Recebemos, assim, as idéias do amarelo, branco, quente, frio [...] e todas as idéias que denominamos de qualidades sensíveis. [...] os sentidos [...] retiram dos objetos externos para a mente o que lhes produziu estas percepções. A esta grande fonte da maioria de nossas idéias, bastante dependente de nossos sentidos, dos quais se encaminham para o entendimento, denomino sensação (Locke, 1999, p. 58).

Diante desse quadro, podemos afirmar que o autor entende a percepção ${ }^{3}$ como o início de todos os materiais do conhecimento. Ela é o primeiro passo para o conhecimento e a primeira operação das faculdades intelectuais dos humanos. Após a percepção, a mente opera o mecanismo

\footnotetext{
${ }^{3}$ Sobre a ideia de causa e efeito, Locke entende que é justamente da observação e/ou percepção que nossos "[...] sentidos tiram da constante vicissitude das coisas, não podemos deixar de observar que vários particulares, não só qualidades como substâncias, começam a existir, e recebem sua existência da devida aplicação e operação de algum outro ser.” Para o autor, é justamente desse fato que aprendemos nossas ideias de causa e efeito. A causa, por conseguinte, é o que faz com que outra coisa, seja substância, ideia simples ou modo, comece a ser algo. A causa, assim, pode criar, gerar, fabricar e pode transformar (Locke, 1999, p. 132).
} 
de reter as ideias por meio da memória (Locke, 1999, p. 80). Ademais, as operações da mente se constituem na segunda fonte de ideias, da seguinte forma:

[...] a outra fonte pela qual a experiência supre o entendimento com idéias é a percepção das operações de nossa própria mente, que se ocupa das idéias que já lhe pertencem. Tais operações, quando a alma começa a refletir e a considerar, suprem o entendimento com outra série de idéias que não poderia ser obtida das coisas externas, tais como a percepção, o pensamento, o duvidar [...] e todos os diferentes atos de nossas próprias mentes. [...] a reflexão significa na mente suas próprias operações, como elas se formam, e como elas se tornam as idéias dessas operações, no entendimento (p. 58).

Dessa forma, todo o conhecimento se funda na sensação ou na reflexão. Isto é, os objetos externos suprem a mente humana com as ideias das qualidades sensíveis, cujas percepções são produzidas nos humanos, e a mente supre o entendimento com ideias, por meio de suas operações, que é justamente a atividade de reflexão, sempre posterior à sensação. $\mathrm{O}$ homem começa a ter ideias, por conseguinte, quando começa a perceber o mundo exterior. As ideias que recebemos das sensações podemos adquirir por meio de um sentido, mais de um sentido, por meio da reflexão e por todos os sentidos e reflexão (p. 60-65).

Além disso, para Locke, não existe conhecimento sem discernimento, ou seja, sem a faculdade da mente humana de discernir e distinguir entre a variedade de ideias. Em suma:

Não basta ter percepção confusa de algo geral. Se a mente não tiver uma distinta percepção dos diferentes objetos e de suas qualidades, será incapaz de alcançar muito conhecimento, embora os corpos que impressionaram nos dominassem como o fazem atualmente, e a mente estivesse pensando continuamente. Decorre da faculdade de distinguir uma coisa da outra a evidência e certeza, ainda que muito gerais, de várias proposições, que passavam por verdades inatas, porque os 
homens, considerando superficialmente a verdadeira causa pela qual estas proposições merecem assentimento universal, as atribuíram inteiramente às impressões inatas uniformes, as quais, na verdade, dependem do discernimento claro da mente, perceba ou não que duas idéias se igualem ou se diferenciem (Locke, 1999, p. 85).

E para chegarmos à verdade, devemos examinar as coisas do modo como realmente são e não do modo como as imaginamos ou fomos ensinados a imaginá-las. No âmbito da ideia lockiana de verdade, devemos distinguir o conhecimento. Para o autor, o conhecimento humano é composto somente de ideias. Esse é o posicionamento de Locke (1999, p. 211): o conhecimento é apenas a percepção do acordo e conexão ou do desacordo e rejeição de ideias. Por isso, somente onde se manifesta essa percepção, há conhecimento. Segundo Locke, para entendermos no que consiste esse acordo ou desacordo devemos entender seus quatro principais modos, são eles:
a) identidade ou diversidade;
b) relação;
c) coexistência ou conexão necessária;
d) existência real (1999, p. 211).

A identidade ou diversidade é o primeiro ato da mente, quando nela têm quaisquer sentimentos ou ideias. Isso porque, para perceber a ideia, a mente deve perceber o que ela é, assim como a sua distinção para com as demais, ou seja, saber que uma ideia não é outra. Além disso, a mente deve compreender a relação, isto é, o que é relativo: a percepção 
a relação entre duas substâncias. Em terceiro lugar, saber a coexistência de substâncias no mesmo objeto. Por fim, saber a existência real de uma substância. $^{4}$ (1999, p. 212-213).

Se existem várias maneiras pelas quais a mente é possuída da verdade e cada uma delas é chamada de conhecimento, devemos, segundo Locke (1999, p. 213), compreender os modos de conhecimento. O conhecimento é atual ou habitual quando se refere à “[...] visão presente do acordo ou desacordo de qualquer de suas idéias, ou da relação que elas têm entre si” (1999, p. 213). Esse conhecimento se desdobra em dois graus, ou seja:

Primeiro, consiste nestas verdades dispostas na memória, que, sempre que ocorrem na mente, esta percebe atualmente a relação que existe entre aquelas idéias. $\mathrm{E}$ isto ocorre em todas estas verdades das quais temos um conhecimento intuitivo, em que as próprias idéias, pela visão imediata, descobrem entre si seus acordos ou desacordos.

Segundo, o outro trata destas verdades sobre as quais a mente tem sido convencida e retém a memória desta convicção, sem as provas. Deste modo, um homem que se recorda com certeza de ter uma vez percebido a demonstração de que os três ângulos de um triângulo se igualam a dois retos está seguro de que sabe isto, porque não pode duvidar dessa verdade. Em sua aderência a uma verdade, cuja demonstração que a tornava primeiramente conhecida já está esquecida, embora um homem

${ }_{4}^{4}$ A ideia de substância sempre foi entendida como realidade primitiva. Locke, contudo, entende que nenhum autor conseguiu claramente especificar o substrato de todos os seus atributos. Para Locke, ao contrário dos demais autores, diz ele, a substância não é uma ideia simples, mas uma ideia composta. O exemplo do ouro, por exemplo, demonstra que ele, enquanto substância, é formado por ideias simples agrupadas, como o amarelo, o denso, o dúctil, etc. Locke afirma a existência real das substâncias, mas destaca que elas não podem ser conhecidas em si mesmas. A tese de Locke é a de que a substância se reduz a uma espécie de infinito em ato, ou seja, existe, mas não se pode saber o que seja, e a única investigação possível é a pesquisa experimental das qualidades que nela coexistem. Nesse sentido, para conhecer a realidade exterior, devemos, segundo Locke, considerar a substância como um conjunto de ideias simples de sensação. De fato, a realidade interior deve ser entendida, segundo esse pensador, como um conjunto de ideias e de reflexão (Locke, 1999, p. 123-127). 
possa julgar preferível acreditar em sua memória do que realmente conhecer, parece-me tal maneira de tratar a verdade como algo entre a opinião e o conhecimento, um tipo de certeza que ultrapassa a mera crença, pois depende do testemunho de outro; no entanto, com base no devido exame, descubro que não se aproxima da certeza perfeita, sendo com efeito conhecimento verdadeiro o que é apto a desviar nossos primeiros pensamentos para o erro neste assunto; decorre do fato de que o acordo ou desacordo entre idéias neste caso não é percebido, como o era inicialmente devida a uma visão atual de todas as idéias intermediárias por meio das quais o acordo ou desacordo dessas na proposição era inicialmente percebido, mas sim por outras idéias intermediárias que mostram o acordo ou desacordo das idéias contidas na proposição de que certamente nos lembramos (Locke, 1999, p. 214).

De fato, a percepção do acordo ou desacordo entre ideias, em Locke, pode ocorrer mediante três vias: a) intuitiva; b) demonstrativa; e c) sensitiva. Intuitivo é o conhecimento que pode ser obtido pela intuição, isto é, por meio de uma simples comparação entre ideias, sendo ele imediato e certo. Por sua vez, o conhecimento demonstrativo impõe a utilização das ideias intermediárias para possibilitar a avaliação do acordo ou desacordo entre as ideias, sendo este um conhecimento menos certo que o intuitivo. Sensitivo é o conhecimento obtido na imediata percepção de um objeto, ou seja, um conhecimento seguro, mas apenas particular.

Se o conhecimento é a percepção de acordo ou desacordo entre ideias, devemos saber o que elas são. As ideias se relacionam à realidade das coisas. As ideias simples são conforme as coisas - a realidade. Elas são introduzidas na mente passivamente por meio da sensação ou reflexão, sem as quais a mente nada pode formular. Elas não são ficções ou fantasias, mas produções regulares e naturais da realidade das coisas exteriores à mente humana. $\mathrm{E}$ assim, para Locke, a conformidade entre as ideias simples e a existência das coisas é suficiente para determinar o conhecimento real (1999, p. 237). 
Quanto às ideias complexas, que não são designadas para serem cópias de algo exterior, nem se referem à existência de algo, mas que se autorrepresentam, jamais podem ser capazes de representação errônea (p. 237). Em suma, uma vez que as ideias simples são introduzidas, a mente exerce seu poder sobre elas de três maneiras:

- combina ideias simples, formando uma ideia composta - complexa.

- reúne duas ideias, simples ou complexas, para ter ideia das relações, ou seja, sem unificar as ideias numa unidade e,

- separa uma ideias de todas as demais que lhes são incorporadas, mediante a abstração, processo pelo qual a mente obtém ideias gerais.

Dessa forma, podemos afirmar que as ideias complexas são formadas de ideias simples (Locke, 1999, p. 91).

Ademais, para continuarmos a compreender o pensamento de Locke, devemos saber o que ele considera a verdade no conhecimento. Para ele, ela é

[...] a união ou separação de sinais, e de que modo as coisas significadas por elas concordam e discordam entre si. A união ou sepa ração de sinais significa aqui o que denominamos por outro nome: proposição. De sorte que a verdade propriamente pertence apenas às proposições, das quais há de dois tipos, a saber, mental e verbal, como há dois tipos de sinais comumente usados, isto é, idéias e palavras (1999, p. 243).

Certeza da verdade aparece quando as palavras reunidas em proposições expressam precisamente 0 acordo ou desacordo das idéias que significam, como realmente é. Certeza do conhecimento consiste em perceber o acordo ou desacordo das idéias, como expressas em qualquer proposição. A isto habitualmente denominamos conhecer, ou estar certo da verdade de qualquer proposição (p. 247). 
A ideia de verdade, nesse sentido, pressupõe a ideia de razão, que, em Locke, significa a “[...] faculdade do homem, que é a faculdade pela qual o homem é suposto distinguir-se das bestas, e pela qual é evidente que ele as ultrapassa” (1999, p. 297). No âmbito do processo do conhecimento, a razão é necessária para a ampliação do conhecimento, assim como para a organização do assentimento humano. Assim,

[A razão] percebe a conexão necessária e indubitável de todas as idéias ou provas entre si, em cada passo de qualquer demonstração que produz conhecimento, do mesmo modo que percebe a conexão provável de todas as idéias ou provas entre si, em cada passo do discurso, para o qual pensará que o assentimento é devido. [...] podemos na razão considerar estes quatro graus: o primeiro e mais alto consiste em descobrir e encontrar provas; o segundo, a disposição regular e metódica das mesmas, colocando-as numa ordem clara e adequada, para tornar sua conexão e força clara e facilmente percebidas; o terceiro consiste na percepção de sua conexão e o quarto consiste em tirar a correta conclusão. Estes vários graus podem ser observados em qualquer demonstração matemática. Sendo que uma coisa é perceber a conexão da parte, como a demonstração é realizada por outra, e outra é perceber a dependência da conclusão sobre todas as partes; a terceira, formular uma demonstração clara e nitidamente; e às vezes diferente de todas estas, ter primeiro descoberto estas idéias intermediárias ou provas pelas quais é formada (Locke, 1999, p. 298).

Ao abordar os limites do conhecimento e as suas formas legítimas - a verdade -, Locke entendeu, conforme vimos, que o conhecimento constitui percepção de conveniência ou de discordância entre ideias e se expressa por meio de juízos. Além disso, importa a correspondência da ideia com o mundo exterior, ou seja, trata-se de uma conveniência que é a “[...] de uma existência real e atual que convém a algo cuja idéia temos na mente”. A percepção da existência é irredutível à percepção de uma relação entre duas ideias, em virtude de a existência não ser uma ideia como a de doçura. Existem várias espécies de certeza com relação à existência 
das coisas. Se uma primeira espécie é intuitiva e provém da reflexão da existência do homem, já a segunda espécie “[...] seria a certeza demonstrativa da existência de Deus. Finalmente, uma terceira espécie é a certeza por sensação, referente aos corpos exteriores aos homens” (Locke, 1999, p. 127-129).

Ademais, a dualidade de juízos, que separam, de um lado, as relações entre ideias, e de outro, as relações que se referem à existência real dos correspondentes às ideias, coloca-se também quanto ao problema da verdade e de sua contraparte, a falsidade. Segundo Locke, existem duas espécies de juízos falsos. Em primeiro lugar, a relação expressa na linguagem não corresponde à relação percebida intuitivamente entre as ideias. Em segundo lugar, o erro não consiste em perceber mal uma relação, mas em percebê-la entre ideias não correspondentes a qualquer realidade.

No primeiro caso, é possível, evitando o erro, formular-se um juízo verdadeiro que, no entanto, não diz respeito à realidade. Somente no segundo caso poderemos ter um real conhecimento, supondo-se dois elementos da verdade: a) a conveniência das ideias entre si e, b) a conveniência das ideias com relação à realidade.

O primeiro caso relaciona-se à ciência das matemáticas e à ciência das morais. No âmbito delas, todo o conhecimento é certo em virtude de seu conteúdo ser as ideias produzidas pela própria mente. $\mathrm{O}$ segundo caso diz respeito às ciências experimentais. A certeza, no âmbito do conhecimento, depende do critério de verificação da conveniência das ideias formuladas pela mente humana à realidade que lhes é exterior. Nesse sentido, o conhecimento, em Locke, é completamente fundado na experiência sensível. Para além dos limites do empirismo, a mente humana formularia ideias que possuem o critério de validez na sua compatibilidade interna, sem que sejam consideradas a expressão de uma realidade exterior. 
Considerando que o conhecimento deve ser verdadeiro, Locke (1999, p. 309) entende que o erro não é uma falha do conhecimento, mas um equívoco de nosso julgamento, que assente que algo não é verdadeiro. Apesar de muitas possibilidades de erro, as mais comuns, segundo o autor, são:

- carência de provas;

- carência de habilidade para usá-las;

- carência de vontade para vê-las;

- medidas errôneas de probabilidade.

Diante do quadro apresentado sobre a Filosofia lockiana, podemos afirmar que o pensador buscou compreender os limites entre a opinião - o senso comum - e o conhecimento. Para cumprir o intento, ele formulou o seguinte método:

Primeiro, investigarei a origem daquelas idéias, noções, ou qualquer outra coisa que lhe agrade a denominar, o que o homem observa, e é consciente de que as tem em sua mente, e o meio pelo qual o entendimento chega a ser delas provido. Segundo, tentarei mostrar que conhecimento e entendimento têm dessas ideias, e a certeza, evidência e extensão delas. Terceiro, farei alguma investigação acerca da natureza e fundamentos da fé, ou opinião; entendo isto como o assentimento que damos para qualquer proposição como verdadeira, ou dessas verdades de que ainda não temos conhecimento certo. Teremos, assim, ocasião para examinar as razões e graus do assentimento (Locke, 1999, p. 30).

Locke (1999, p. 30) buscou compreender a extensão do entendimento humano e até onde as faculdades humanas podem alcançar a certeza. Ele entendeu que todo o conhecimento advém da experiência sensível e de sua reflexão. Quer dizer que a experiência e a reflexão não se constituem no próprio conhecimento, mas são os processos que suprem a mente com os materiais - as ideias - do conhecimento. As ideias são 
todo e qualquer conteúdo do processo cognitivo. As ideias de sensação provêm do exterior, enquanto as de reflexão têm origem no próprio interior do indivíduo.

Essas duas categorias de ideias, chamadas por Locke de simples, são recebidas passivamente pelo entendimento do ser humano. Ideias simples são as que advêm de experiências concretas, as quais fornecem três tipos de ideias simples: as de sensação (quente, sólido, duro, etc.), as de reflexão (a atenção, a memória, a vontade, etc.) e de ambas ao mesmo tempo (existência, duração, número, etc.). A partir das ideias simples, Locke se questiona se elas são representativas de coisas exteriores percebidas pelo humano. Para responder, o autor divide as ideias simples em dois grupos. O primeiro é formado pelas ideias enquanto percepção dos sentidos. O segundo, enquanto modificações da matéria nos corpos causadores de tais percepções, ou seja, podem afetar os sentidos humanos.

Em Locke, por conseguinte, as ideias de sensação e as ideias de reflexão são as únicas fontes de todo o entendimento humano, que é um mundo composto de operações mentais e coisas sensíveis que possuem existência objetiva. Ainda assim, não podemos deixar de considerar que no pensamento desse autor todo e qualquer conhecimento do mundo exterior era decorrente desse mundo, assim como dos sentidos humanos que apreendem os fenômenos do mundo. De fato, o conhecimento humano, nesse sentido, é limitado. O homem não pode conhecer, segundo Locke, todas as características dos objetos. Ele irá conhecer conforme a possibilidade de seus sentidos internos e externos.

Apesar da impossibilidade de um conhecimento pleno ou, em outras palavras, muito embora Locke não considere possível o homem descobrir a substância da matéria e, mais ainda, de demonstrar a existência da matéria, ainda assim o pensador defendeu que não se poderia afirmar a inexistência da matéria. $\mathrm{O}$ fato de não podermos prova que ela existe, entendeu Locke, não implica provar o contrário, isto é, que ela não existe. Para ele, o 
mundo material existe. Mais do que isso, ele afirmou que o conhecimento somente ocorre por meio da experiência. Em outras palavras, isso equivale a dizer que o conhecimento, que se constitui de ideias, ocorre em sua relação com o mundo material sensível.

\section{A CRÍTICA LOCKIANA AO INATISMO: a Questão dos Princípios Universais}

No caminho da compreensão do conhecimento, Locke (1999, p. 37) percebe que a primeira investigação consiste em verificar como as ideias aparecem na mente. Esse pensador iniciou o seu Tratado sobre o Entendimento Humano com a indagação sobre a extensão e o limite do entendimento humano e criticou a doutrina das ideias inatas, próprias do pensamento racionalista clássico, como o racionalismo cartesiano, para o qual o ser humano nasce com conhecimento, independentemente das suas experiências. Ele se insurgiu contra a afirmação provinda do inatismo dos racionalistas, que propunha existir ideias inatas e verdadeiras nos humanos, acessíveis por meio da razão. Segundo o autor,

a maneira pela qual adquirimos qualquer conhecimento constitui suficiente prova de que não é inato. Consiste numa opinião estabelecida entre alguns homens que o entendimento comporta certos princípios inatos, certas noções primárias, [...] caracteres, os quais estariam estampados na mente do homem, cuja alma os recebera em seu ser promordial e os transportara consigo ao mundo. Seria suficiente para convencer os leitores sem preconceito da falsidade desta hipótese se pudesse apenas mostrar [...] como os homens, simplesmente pelo uso de suas faculdades naturais, podem adquirir todo conhecimento que possuem sem a ajuda de impressões inatas e podem alcançar a certeza sem nenhuma destas noções ou princípios originais (1999, p. 38). 
Partidário da tese inatista do conhecimento, o filósofo racionalista francês René Descartes (2006) promoveu a construção de uma metodologia que permitisse o conhecimento científico dos fenômenos da natureza, ou seja, uma metodologia que proporcionasse o conhecimento seguro e verdadeiro, iluminado por certezas racionais. Para tanto, Descartes supôs que a ciência devesse se constituir de uma pretensão de universalidade, que poderia ser concebida por apenas um único indivíduo, visto que todos são dotados natural e igualmente de razão.

Em síntese, o método cartesiano de conhecimento se deve ao imperativo da razão. Segundo esse pensador, se conhecemos o fenômeno complexo a partir de um encadeamento mais simples, a dedução nos permite a razão e a certeza, tal como ocorre com as regras da aritmética (Descartes, 2006, p. 30-50). Assim, o conhecimento seguro - científico - decorre de ser a razão humana abstrata e essencialmente elevada à última potência. Mesmo que não se possa dizer que a razão sugere ao homem tudo aquilo que ele pensa ou imagina, todas as ideias devem conter um fundamento de verdade, pois que a figura do bom Deus, criada por Descartes como contraposição à ideia da existência do gênio maligno, concedeu razão a todos os humanos como um instrumento universal (2006, p. 48-50).

Em Descartes (2000, p. 269-290), a figura de Deus aparece como ser perfeito e supremo ante a imperfeição humana, dotado da luz racional e fundamento último da objetividade. É justamente esse Deus Sol (a razão) que ilumina naturalmente os homens com a racionalidade. Ou seja, para o autor, se Deus existe, ele não permite o erro humano e dota todos os homens de razão. Daí que as ideias racionais correspondem à realidade verdadeira. E assim, a verdade se deduz da razão natural e pura, alheia à demonstração.

Locke concorda com Descartes que o conhecimento se constitui de ideias, mas diverge da noção de que elas sejam inatas no ser humano, suposição que, em última instância, recorre a uma justificação externa, 
como a ideia de Deus, quando o conhecimento filosófico deveria se justificar a si mesmo. De fato, contrapondo-se ao pensamento racionalista, que percebe a razão de maneira inata e universal, Locke (1999, p. 37) argumenta que nem todas as pessoas nascem com os mesmos conhecimentos, assim como nem todos os humanos conhecem os princípios da identidade e da contradição lógica. Além disso, as crianças, por exemplo, não possuem os mesmos conhecimentos dos adultos. Mais ainda, o conhecimento depende do contexto no qual cada ser humano está inserido, como a localidade geográfica. Quer dizer, as pessoas não possuem o mesmo conhecimento em virtude da ausência de um conjunto de vivências que lhes concederia as ideias necessárias ao conhecimento.

Não há, por conseguinte, princípio que possa ser considerado inato ou universal. Para Locke (1999), todos dependem da experiência prévia dos sentidos. Para corroborar tal ideia, o autor invoca a diversidade cultural para comprovar que não existe princípio inato: nações inteiras divergem com relação a princípios consagrados em outras nações. Ou seja, sujeitos e povos podem divergir ou convergir acerca de regras práticas morais, conforme experiências e vivências.

Nesse sentido, os princípios inatos não são universais e, por isso mesmo, o inatismo é uma falsa doutrina. Pelo contrário, o empirista Locke afirmava que os conhecimentos começam com a experiência dos sentidos: o conhecimento inicia-se da percepção, organizada pelo entendimento, não mediante propriedades inatas e desconectadas do mundo exterior. Daí o porquê de ter afirmado que somos tábulas rasas, isto é, folhas de papel em branco, prontas a serem preenchidas pelas experiências, conforme veremos adiante.

Esse pensador afirma a inexistência das ideias inatas ou, em outras palavras, a inexistência das ideias impressas na mente, visto que “[...] um homem pode viver longamente, e, finalmente, morrer ignorando muitas verdades que sua mente seria capaz de conhecer” (1999, p. 38-39). De 
certa forma, isso implica afirmar que a capacidade é inata, mas o conhecimento deve ser adquirido por meio da experiência. Nesse sentido, a razão humana não é vista como uma razão apriorística, mas como a faculdade da mente de deduzir verdades desconhecidas de princípios ou proposições já conhecidos pelo ser (Locke, 1999, p. 39-40).

Conforme afirmaram Andery, Micheletto e Sério (2007), Locke criticou os vários argumentos que sustentaram o inatismo, da seguinte maneira:

Criticava principalmente o argumento de que a concordância universal seja prova da existência de princípios inatos, já que, segundo ele, para demonstrar que tais idéias eram universais, o que poderia ser facilmente negado se se olhasse, por exemplo, para as crianças que não têm qualquer desses princípios e só os adquirem com o tempo, ou para outros povos que jamais desenvolveram idéias como a de Deus (p. 222).

Locke criticava também o argumento de que essas idéias só se revelavam pelo uso da razão, ou seja, que as idéias inatas estariam impressas na mente, mas só seriam reconhecidas quando de desenvolvesse a razão. Segundo Locke, esse argumento poderia ser rejeitado porque há manifestação do uso da razão antes que se reconheçam as idéias inatas. Além disso, se o uso da razão fosse necessário para o reconhecimento de uma idéia inata não se teria como distinguir uma idéia inata de uma não inata [...] ou seria necessário supor todas as idéias como inatas (p. 222)

O modo como adquirimos conhecimento constitui, por si só, a prova de que o conhecimento não é inato, mas adquirido por meio das faculdades humanas. Daí porque Locke discutiu os processos que permitiram ao homem adquiri-lo. O conhecimento é, nesse sentido, constituído de ideias, que tanto de relacionam a objetos externos quanto a operações internas da mente. Por sua vez, as ideias, no pensamento de Locke, se fundam na experiência, externa e interna (Locke, 1999, p. 37) 
Noutros termos, no pensamento de Locke, “[...] a idéia é ao mesmo tempo o efeito produzido por um objeto do mundo exterior sobre o entendimento e a modificação sofrido pelo entendimento" (Tadié, 2005, p. 115). Ela é o resultado e o próprio processo de aprendizado. Fundamentada a experiência interna e externa, a experiência não é apenas sensação - percepção do mundo exterior -, mas igualmente reflexão: consideração da mente de suas próprias operações.

Por meio de sua crítica à doutrina inatista do conhecimento, Locke entendeu que o ser humano nasce como uma tábula rasa, uma espécie de papel em branco, na qual serão impressos caracteres - conhecimentos - no decorrer da vida, por meio das experiências e percepções dos sentidos. O empirista Locke entendeu que as ideias estão no intelecto quando estiveram anteriormente nos sentidos: o conhecimento se funda na experiência.

Diante disso, Locke questionou quais os elementos constitutivos do conhecimento, suas origens e processo de formação, sua amplitude e sua aplicabilidade. Assim como os demais epistemólogos de seu tempo, ele pôs em questão: Qual o fundamento de um conhecimento certo e indubitável? O desígnio de Locke, nesse sentido, foi o de investigar a origem, certeza e extensão do conhecimento humano. Para tanto, o autor se preocupou com as faculdades humanas e como elas são empregadas sobre os objetos que lhes dizem respeito (Locke, 1999, p. 29).

Tendo comparado a mente humana a uma tábula rasa, Locke entendeu que o conhecimento ocorre da seguinte maneira:

Os passos pelos quais a mente alcança várias verdades. Os sentidos inicialmente tratam com idéias particulares, preenchendo o gabinete ainda vazio, e a mente se familiariza gradativamente com algumas delas, depositando-as na memória e designando-as por nomes. Mais tarde, a mente, prosseguindo em sua marcha, vai abstraindo, apreendendo gradualmente o uso dos nomes gerais. Por este meio, a mente vai se 
enriquecendo com idéias e linguagem, materiais com que exercita sua faculdade discursiva. E o uso da razão torna-se diariamente mais visível, ampliando-se em virtude do emprego desses materiais. Embora a posse de idéias gerais, o uso de palavras gerais e a razão geralmente cresçam juntos, não vejo como isso possa de algum modo prová-las inatas. Concordo que o aparecimento de algumas verdades aparece bem cedo na mente, mas de modo tal que mostra que não são inatas. Pois, se observarmos, descobriremos que isto continua também com as idéias não-inatas, mas adquiridas, sendo aquelas primeiras impressas por coisas externas, com as quais as crianças se deparam bem cedo, ocasionando as mais frequientes impressões em seus sentidos. Nas idéias assim aprendidas, a mente descobre que algumas concordam e outras diferem, provavelmente tão logo tenha uso da memória, tão logo seja capaz de reter e receber idéias distintas. Mas, quer isto seja ou não existente naquele instante, uma coisa é certa: existe muito antes de uso de palavras, ou chega antes do que ordinariamente denominamos "o uso da razão". Pois uma criança sabe como certo, antes de poder falar, a diferença entre as idéias de doce e amargo (isto é, que o doce não é amargo), como sabe depois (quando começa a falar) que a amargura e a doçura não são a mesma coisa (1999, p. 41-42).

Se o conhecimento não é nem universal nem inato, Locke afirma que todo e qualquer conhecimento do mundo exterior somente ocorre em decorrência desse mundo, assim como dos sentidos humanos que apreendem os fenômenos do mundo. Por consequência, o conhecimento humano é limitado: o homem não pode conhecer, segundo Locke, todas as características dos objetos.

O conhecimento advém da experiência e será verdadeiro quando guardar correspondência entre a ideia e aquilo que a produz - a realidade percebida. Para Locke, não percebemos o mundo sensível como ele é, mas como ele nos parece ser. Conforme afirma Tadié, o conhecimento da realidade sensível é mediado pelas estruturas do entendimento, de 
maneira que a "[...] brancura não existe na bola de neve, mas a bola de neve possui o poder de produzir a ideia de brancura em nosso entendimento" (2005, p. 103).

O primeiro dos limites do conhecimento humano é a ausência de acesso imediato ao mundo real, muito embora esse fato não impeça os humanos de formularem juízos verdadeiros sobre os fenômenos do mundo, desde que guardem correspondência entre o objeto e a representação que se faz dele por meio das ideias. Existe um contínuo processo de validação pelo teste da correspondência entre a representação e a realidade compreendida, mas a razão (inata) não possui a capacidade de sustentar a obtenção da verdade, dependendo da experiência. O homem irá conhecer conforme a possibilidade de seus sentidos internos e externos. O conhecimento somente ocorre por meio da experiência. Ele se constitui de ideias, mas somente ocorre em sua relação com o mundo material sensível.

\section{DIREITOS HUMANOS UNIVERSAIS E INATOS: Aportes Para a Defesa da Satisfação das Necessidades de uma Vida Digna}

A intenção de abordar o tema dos direitos humanos leva-nos a afirmar, de maneira prévia, que o liberalista Locke (1994, cap. III-VI), em seu contrato social, buscou tornar possível a inversão da condição do humano, para considerar todos aqueles a quem interessava ao colonialismo inglês, a perda da condição de humano e, por conseguinte, a assunção de sua não racionalidade. Isso quer dizer que, por mais que nenhum humano possa abdicar de sua liberdade e humanidade, quando se entra em uma guerra injusta, perde sua humanidade e o prejudicado pode apropriar-se de seus bens e escravizá-lo legitimamente. E assim, toda a guerra da burguesia 
passou a ser considerada uma guerra santa, justa e em defesa dos direitos humanos, contra adversários que realizam uma guerra injusta e contrária aos direitos humanos (Locke, 1994, cap. VI).

Dessa maneira, Locke inverte o protótipo de direitos humanos, que ainda hoje em dia constitui o marco de categoria do imperialismo liberal: em se tratando de guerras justas, ou seja, em nome dos direitos humanos, violam-se os direitos humanos, mas os adversários não podem reclamar esses direitos para si, posto que previamente os violaram.

Locke, inclusive, justificou a possibilidade da escravidão nos casos em que a pessoa perde o seu direito à vida, como nos casos de pena de morte $(1994$, p. 43).

Apesar da justificação ideológica de Locke, violadora da dignidade do ser humano, no âmbito desse artigo abordaremos apenas a sua concepção epistemológica empirista e a sua tese contrária ao inatismo do conhecimento via razão e inatismo dos princípios considerados universais. Por mais que seja difícil a separação entre o posicionamento ideológico e científico ou epistemológico de um pensador, focaremos exclusivamente na epistemologia de John Locke, desconsiderando o seu pensamento político, econômico, social e ideológico.

De fato, epistemologicamente Locke afirmou que o conhecimento não é nem universal nem inato. Tampouco os princípios e valores são inatos e universais para todos os humanos, variando contextual e historicamente. Os princípios práticos, segundo Locke, não possuem uma recepção universal. Segundo ele:

Penso que será difícil ilustrar qualquer regra moral com a mesma pretensão de ter o assentimento geral e imediato da que dizer $o$ que $e ́, e ́$, ou ter uma verdade tão manifesta como esta: é impossível para uma mesma coisa ser e não ser. Por mais que seja evidente que elas se distanciem posteriormente do título de inatas, a dúvida de que elas são impressões nativas na mente é muito mais forte em relação aos 
princípios morais do que aos outros. Nem isto coloca de modo algum sua verdade em questão. Elas são igualmente verdadeiras, embora não igualmente evidentes.

A fé e a justiça não são compreendidas por todos os homens como princípios. Para averiguar se existe um destes princípios morais acerca dos quais todos os homens concordam, sou levado a apelar para alguém que esteja moderadamente familiarizado com a história da humanidade, que tenha olhado além da fumaça de sua própria chaminé. Onde se encontra esta verdade prática, recebida universalmente, sem dúvida ou questão, como devia ser se fosse inata? A justiça e a conformidade ao contrato consistem em algo com que a maioria dos homens parece concordar. Constitui um princípio julgado estender-se até aos esconderijos dos ladrões e às confederações dos maiores vilões; e os que se afastaram a tal ponto da própria humanidade conservam entre si a fé e as regras da justiça. Concordo que os próprios proscritos agem, deste modo, entre si, mas sem que isto seja recebido como leis inatas da natureza. Praticam-nas como leis de conveniência dentro de suas próprias comunidades, sendo impossível imaginar que a justiça é vista como um princípio prático [...] (1999, p. 45).

Mais do que isso, este pensador afirmou que, além de não existirem princípios universais, existem princípios contraditórios no mundo:

Admito facilmente que há grande número de opiniões que homens de diferentes países, educação e temperamentos receberam e aceitaram como os primeiros e inquestionáveis princípios. Vários deles, porém, não só por seu absurdo como por sua recíproca oposição, revelam a impossibilidade de que sejam verdadeiros. Embora inúmeras dessas proposições estejam bem afastadas da razão, são a tal ponto sagradas para uma ou outra região que mesmo os homens de bom entendimento em outros assuntos bem cedo as compartilham em suas vidas, e, seja o que for que lhes é o mais querido, têm sua verdade submetida a dúvidas, ou questões (1999, p. 48). 
De fato, Locke (1999, p. 46) afirma: "Como as regras morais necessitam de prova, elas não são inatas”. Continuando o raciocínio de que os homens têm princípios práticos opostos, o pensador argumenta:

Quem investigar cuidadosamente a história da humanidade, examinar por toda parte as várias tribos de homens e com indiferença observar suas ações será capaz de convencer-se de que raramente há princípio de moralidade para ser designado, ou regra de virtude para ser considerada

Nações inteiras rejeitam várias regras morais. Poder-se-á, talvez, objetar que não consiste num argumento afirmar que a regra não é conhecida porque é violada. Concordaria com a validade desta objeção se os homens, embora transgressores, não repudiassem a lei, pelo temor da vergonha, da crítica ou do castigo, que imporiam algum respeito sobre eles. Mas é impossivel imaginar que toda uma nação de homens devesse rejeitar e renunciar publicamente ao que cada um deles sabia com certeza e infalivelmente ser uma lei, pois deviam tê-la naturalmente em suas mentes (1999, p. 47).

A importância da retomada epistemológica de Locke reside justamente na crítica ao inatismo dos princípios universais de direitos humanos, conforme veremos. A delimitação conceitual dos direitos humanos induz a uma problemática em razão dos necessários cortes semânticos e epistemológicos procedidos por diversos pensadores no intuito de estudar histórica e evolutivamente os direitos humanos. Os direitos humanos poderiam ser estudados desde as origens da civilização ocidental, no desígnio de comprovar a evolutividade da condição humana, abstrata ou concretamente dotada de direitos.

Por outro lado, também se poderia investigar as demais formas de manifestação da necessidade de direitos e de dignidade, em culturas diversas, lugares geográficos distantes e a partir da questão místico-religiosa dos diferentes povos. Daí se poderia estudar, por exemplo, o que se considera direitos humanos e como se dá a luta e o reconhecimento desses 
direitos em tribos africanas remotas, em tribos indígenas brasileiras, em grupos culturais latino-americanos, etc. Também poderia se examinar, por exemplo, como ocorreu a constituição das lutas por dignidade nos países orientais. Mais ainda, o que é considerado direitos humanos pelos países muçulmanos, nos quais a religião (o Alcorão) confunde-se com o próprio poder político.

Da mesma forma, poderia ser investigado se, mesmo após a globalização da visão ocidental dos direitos humanos (universalização), mesmo assim coexistem modos culturalmente diferentes de se travar a luta por dignidade. A visão dos direitos (princípios de direitos humanos) de origem ocidental, contudo, prevaleceu sobre as demais, haja vista o processo de desenvolvimento histórico do mundo, que culminou na universalização dos valores ocidentais a todos os cantos do globo, sob o discurso da neutralidade das normas e idealização abstrata dos humanos, ou seja, em todos os lugares os homens são considerados iguais em essência (idealmente), portadores dos mesmos valores e princípios (universalização da ideia inatista), e, portanto, as mesmas garantias jurídicas devem ser aplicadas.

Trata-se, nesse sentido, da ideia cartesiana da pretensão de universalidade (dos princípios de direitos humanos) que poderia ser concebida por um único indivíduo (ou o Ocidente hegemônico), uma vez que todos são dotados natural e igualmente de razão. Nessa esteira, a Declaração Universal dos Direitos Humanos de 1948 decretou que todos são iguais em direitos inalienáveis, ou seja, que todos têm direitos por terem nascido humanos.

Concretamente, todavia, os princípios inatos de direitos não recaem sobre a totalidade da população mundial. Exemplo disso é a população do Zimbabue, país no qual a taxa de pobreza de rendimento situa-se em $62 \%$. Podemos dizer que são essas pessoas iguais em direitos inalienáveis por terem nascido humanas? Mais ainda, se falarmos dos habitantes de Zâmbia, país que apresenta a quinta taxa mais elevada de prevalência de HIV no 
mundo e no qual a falta de recursos revela uma taxa de $63 \%$ da população que sofre de pobreza multidimensional, vivendo com o equivalente a menos de 1,25 dólar por dia. Será que essas pessoas têm direitos pelo simples fato de terem nascido humanas? (Nações Unidas, 2010, p. 32).

Ademais, o número absoluto de pessoas subnutridas (consumo energético mínimo) pouco se modificou dos 850 milhões de pessoas desde o ano de 1980. Desse total, 63\% referem-se a pessoas provenientes da Ásia e do Pacífico, 26\% da África Subsaariana, e apenas 1\% dos países desenvolvidos. Assim, enquanto milhões morrem de fome ou têm o mínimo para comer, milhões comem em demasia (Nações Unidas, 2010, p. 38). O que não podemos esquecer, conforme Sen (1983), é que a fome não reflete a escassez de alimentos, mas a falta absoluta de meios para alcançá-los.

Tradicionalmente, desde as formulações dos séculos 15-18, os direitos humanos construídos ocidentalmente confundem-se nos planos da realidade e da razão, visto serem considerados naturais, instituídos e universais. Isso que dizer, utiliza-se de meios jusnaturalistas (qualidade essencial e idealista do humano) para alcançar fins positivistas (reconhecidos positivamente e garantidos universalmente), sob uma linguagem descritiva e, não por isso, sociológica, ou seja, sob uma falácia normativista.

Para termos uma boa noção do que foi expresso, analisemos, por exemplo, a Declaração Universal dos Direitos Humanos (1948) que, em que pese em seu Preâmbulo declarar alguns ideais a serem alcançados, universaliza esses ideais para todos e todas no mundo. Além disso, paradoxalmente, aceita a noção de colonialismo e imperialismo ao dispor sobre a necessidade de se assegurar os direitos humanos inclusive dos territórios sob a jurisdição. Dessa forma, coloca os colonizadores em patamar superior e os colonizados no papel de inferioridade bárbara.

Ao reconhecer, em seu Preâmbulo, a dignidade de nascimento, ou seja, todos e todas detêm direitos humanos e dignidade humana pelo simples fato de terem nascido humanos, faz de todos e todas iguais em 
direitos inalienáveis. Os direitos, contudo, não são inatos, ou seja, a satisfação das necessidades não é automática em razão da simples existência de direitos abstratos. A linguagem normativa é sempre deôntica: trata-se de um ideal a atingir, uma proposta de dever ser que deve ser alcançada por todas as pessoas em todas as nações, para que se ensine a educação, o respeito pelos direitos e liberdades, tanto em âmbito nacional quanto internacional, para as populações de seus territórios ou, como já mencionado, de territórios sob a sua jurisdição.

Já nos artigos $1^{\circ}$ e $2^{\circ}$ considera que todos os humanos nascem livres e iguais em dignidade e direitos. Após, que todos esses direitos referem-se aos direitos dispostos na Declaração, sem distinção qualquer, seja ela de raça, cor, gênero, religiosa, política, etc. Não mais são, portanto, um dever ser a alcançar ou uma luta por direitos a se travar, mas o próprio ser. todos que nascem humanos têm direitos humanos assegurados, pelo simples fato de terem nascido humanos.

Aí reside a importância em distinguirmos entre as idéias que inspiraram essa construção teórica da Declaração Universal e a realidade à qual é aplicada. Isso porque a enunciação de igualdade formal parte de um conceito de homem em abstrato, não dos homens concretos situados imanentemente no mundo e na História. Não podemos negar que seja uma conquista jurídica que incorpora o postulado da igualdade ao Direito Positivo em escala mundial. Por detrás dessa positivação, todavia, a realidade é múltipla e a igualdade de condições de acesso aos bens necessários à vida digna é exceção. "Multidões - especialmente no Terceiro Mundo não nascem livres de cadeias como a desnutrição, a doença, a falta de lar e de emprego, do que estão isentos os privilegiados” (Aldunate, 1991, p. 125-126).

Nesse ponto reside uma das questões mais importantes. Ao mesmo tempo em que o ser humano detém a liberdade para racionalmente fixar prioridades e agir conforme algumas concepções valorativas, não pode- 
mos esquecer que além dessa liberdade de escolha racional, o ser humano também as define de acordo com suas necessidades materiais (Fleiner, 2003, p. 11). Os princípios de direitos humanos não são inatos nem universais em razão da contextualidade e temporalidade de cada ser humano: os valores e as necessidades materiais e imateriais de cada pessoa, grupo ou povo. Para além do universalismo culturalista da visão ocidental dos bens necessários à garantia da dignidade humana, também devemos atentar para as necessidades de cada cultura em particular.

Além disso, o fato de que tanto essas necessidades materiais quanto os meios de sua satisfação estão predeterminados, em que pese não absolutamente, pelo contexto no qual se situa cada ser humano, histórica e geograficamente, o que faz com que uns detenham maior facilidade e outros quase a impossibilidade de suprir suas carências por bens aptos a garantir uma vida digna.

De fato, conforme afirmou Locke sobre os princípios, não há princípio (mesmo de direito humano) que possa ser considerado inato ou universal. Nesse sentido é que o pensador mencionado invocou a diversidade cultural para afirmar que nações inteiras divergem com relação a princípios consagrados em outras nações: sujeitos e povos podem divergir ou convergir acerca de regras práticas morais, conforme experiências e vivências.

Assim sendo, qualquer análise teórica ou prática social que vise à proteção e efetivação dos direitos humanos, mas que ignore as diferenças culturais e os fatos de violação à dignidade, não só devem ser entendidos como teorias desvencilhadas do real e alheias ao mundo imanente, mas também como um apoio indireto às violações, em virtude da ausência do compromisso ético que deve ser assumido na pesquisa, teorização e prática da defesa da vida e da dignidade. 
Perceber que na vida cotidiana os direitos assegurados social e institucionalmente aos humanos diferem em razão direta a sua condição social, gênero, nacionalidade, etc., implica admitir que, por mais que não sejam respeitados e não haja possibilidade de exercê-los, os direitos estão ali, garantidos. Além das diferenças, portanto, não haveria necessidade de uma busca pela instituição, pois todos os humanos já os têm.

Podemos exemplificar da seguinte forma: todos os humanos têm necessidade de uma vida digna, ou seja, de dignidade humana, mas não necessariamente do direito (positivado) à dignidade humana, pois este somente garante, de maneira posterior, a necessidade pelo bem imaterial dignidade e, mais do que isso, somente existe a partir dessa necessidade humana, vindo a confirmá-la institucionalmente. Além disso, nem todos têm a necessidade do acesso aos mesmos bens materiais e imateriais, visto que as culturas, o modo de produção, o modo de vida divergem nas diferentes regiões do mundo.

Para Sánchez Rubio (1999, p. 178), com os bens (sociais) os humanos satisfazem suas necessidades. Os direitos humanos (positivados), por sua vez, são bens (jurídicos) que demarcam as formas e modos de satisfação dessas necessidades, bem como os limites da ação humana, que poderão ser maiores ou menores, em razão do grau de reconhecimento e satisfação das próprias necessidades. As realidades normativas e institucionais dos direitos humanos se constroem ao longo do tempo socialmente, a partir da práxis social e da produção de necessidades, que culminam num processo de valorização coletiva de bens.

Considerando a capacidade humana de criar e recriar a realidade, a partir de sua atuação no mundo, o jusfilósofo espanhol Joaquín Herrera Flores (2009a, 2009b) sistematizou, a partir da teoria crítica dos direitos humanos, uma (re)invenção dos direitos humanos, para que as pessoas possam construir um mundo humanizado e libertário, instituinte de todos os povos em suas diferenças culturais. A partir desse marco de reinven- 
ção, os direitos humanos passaram a ser percebidos em uma constante mobilidade, em uma contínua transformação. Nesse sentido, eles não são entendidos como uma categoria inata e universal, mas como um construído contextual.

Direitos, nessa perspectiva, não se reduzem a direitos - normas legais - juridicamente postos. Eles estão no mundo da prática cotidiana. São os anseios das pessoas por uma vida digna e pela dignidade humana. São processos ${ }^{5}$ de lutas pelo acesso igualitário aos bens materiais e imateriais a uma vida digna de ser vivida, sejam eles de expressão, convicção religiosa, educação, moradia, trabalho, meio ambiente, cidadania, alimentação sadia, lazer, formação, patrimônio histórico, cultural, etc. Então, os direitos humanos, enquanto processos provisórios de lutas, são sempre o resultado transitório pela vida digna.

Por outro lado, direitos humanos podem ser positivados, em que pese nunca definitivamente, com o fim de obtenção de garantias jurídicas para facilitar sua eficácia, efetividade e validade. Para Herrera Flores (2009a, p. 34), antes de se falar em direitos, há que se referir aos bens materiais e imateriais que garantem a dignidade da vida humana, pois

\footnotetext{
${ }^{5}$ Em sentido parecido, para Rubio, são processos de abertura e consolidação de espaços sociais de luta pela dignidade humana (Sánchez Rubio, 1999, p. 162). Dussel, em sua Filosofia da Libertação, percebe os variados modos como se edificam processos de libertação. Afirma a necessidade de os sujeitos históricos, conformados por indivíduos e grupos em posição de desigualdade frente a outros, seja de classe, de etnia, de gênero, etc., tomarem consciência do estado de vitimização em que se encontram e de reagirem criticamente pela afirmação e reconhecimento de suas vidas, de se afirmarem como sujeitos atuantes (Dussel, 1977, p. 83-89). No âmbito da filosofia da libertação, corrente latino-americana da teoria crítica voltada para a dignidade humana, Martín-Baró indica a necessidade fundamental de os sujeitos-atores desenvolverem processos críticos e alternativos para se apropriar do poder de cada época e de cada contexto específico, no intuito de que toda a sociedade possa participar da transformação da realidade em todas as suas dimensões (1988, p. 320, 340-341).
} 
aqueles somente serão provisoriamente o resultado das lutas sociais, políticas, econômicas, comunitárias, etc., pelo acesso aos bens aptos a garantir uma vida digna.

Dentro de uma ética de direito humanos Herrera Flores (2009a, p. 36, 2009b) busca a subversão do instituído. Considera desigualitários os processos de divisão do fazer humano (divisão social, sexual, étnica, territorial), que fazem com que uns tenham mais facilidade em obtê-los e outros tenham mais dificuldade, quando não de impossibilidade. Por conseguinte, a luta por direitos decorre da necessidade que todos e todas têm de acesso aos meios para lutar e aos bens materiais e imateriais a uma vida digna de ser vivida.

Dessa forma é que Arruda Júnior e Gonçalves (2004, p. 36) consideram o universalismo nada mais do que um culturalismo de corte ocidental hegemônico, ou seja, os direitos humanos são justificáveis em razão de sua universalidade, forjada no pensamento iluminista ocidental.

Ao reconhecermos esse contexto de surgimento e de justificação, podemos começar a compreender as dificuldades que encontram outras formas de vida, não dominadas de um modo tão absoluto pelo capitalismo e suas correspondentes formas de poder, em aceitar a categoria direitos humanos. Dito isso, ainda que grande parte das teorias que fundamentaram e das normas jurídicas que positivaram os direitos humanos funcionaram de acordo com o desenvolvimento da racionalidade capitalista, não se pode invisibilizar os processos de conteúdo ético de antagonismo e de criação de alternativas ao instituído social, política, cultural e economicamente. Nesse sentido é a crítica culturalista à noção de direitos universais, os quais não passam de uma universalização de valores culturais ocidentais (Marx, 2000, p. 30-40).

Resulta, portanto, a importância em começarmos a construir uma visão na qual o bem como maior valor axiológico seja a dignidade humana, na conjunção vida digna, liberdade individual e social, assim como igual- 
dade formal e material. Entre a vida, a liberdade e a igualdade, não pode haver hierarquia, pois cada um, isolado, não passa se fragmento: existem conjuntamente.

\section{CONSIDERAÇÕES FINAIS}

Este artigo, que tem por objeto a epistemologia empirista de John Locke, objetivou investigar, epistemologicamente, a crítica de Locke à Filosofia racionalista do inatismo das ideias e princípios, no intuito de averiguar a noção inatista da universalidade (ou universalização) dos direitos humanos. Por meio de uma metodologia dedutiva, o texto problematizou epistemologicamente a garantia universal dos direitos humanos e a sua eficácia concreta no desenvolvimento da vida digna, material e imaterialmente.

Diante disso, em primeiro lugar apresentamos a teoria empirista de John Locke, para a qual todo o conhecimento advém da experiência sensivel, por meio da percepção, que é sempre o início do conhecimento. Locke preocupou-se com a constituição e o processo de produção do conhecimento humano: buscou compreender o que é o entendimento e percebeu que ele se funda da experiência. Daí o porquê de ser considerado empirista.

A compreensão do conhecimento implicou saber como as ideias aparecem na mente. Para Locke, as ideias não são inatas, mas derivam da sensação ou reflexão que advém da percepção. Em suma, quer dizer que o humano, ao travar contato com a realidade exterior, tem uma percepção. Dessa percepção, é sensação a relação do homem com o objeto sensível externo e, posteriormente, reflexão à operação interna de sua mente. Em última instância, o conhecimento ocorre da seguinte maneira: os objetos externos suprem a mente humana com as ideias das qualidades sensí- 
veis, cujas percepções são produzidas nos humanos, e a mente supre o entendimento com ideias, por meio de suas operações, que é justamente a atividade de reflexão, sempre posterior à sensação.

Em segundo lugar, analisamos a crítica de Locke à noção racionalista do inatismo do conhecimento e das ideias. O pensador criticou a doutrina segundo a qual o humano nasce com conhecimento independentemente da experiência. Inexiste, para ele, qualquer ideia inata e verdadeira acessível por meio da razão. De fato, a maneira pela qual adquirimos conhecimento - a experiência - já é prova suficiente de que o conhecimento não é inato.

Se, para Locke, todo o conhecimento origina-se da experiência, não existe o conhecimento racional a priori ou o conhecimento de princípios inatos, mas somente a percepção da experiência para a formação do conhecimento. Todo o conhecimento, por conseguinte, dá-se em decorrência do mundo e dos sentidos humanos que apreendem os fenômenos do mundo.

Por fim, apresentamos a crítica epistemológica de Locke ao inatismo para pensarmos a concepção da universalidade dos direitos humanos, em contraposição à noção da vida digna material e imaterial.

Os direitos humanos, tal como são entendidos modernamente, são a globalização (universalização) de uma visão específica de mínimo de vida digna, ainda que coexistam modos culturalmente diferentes de se travar a luta por dignidade. Nesse sentido, a visão dos princípios de direitos humanos de origem ocidental hegemônica prevaleceu sobre as demais. Dessa maneira, o discurso da neutralidade das normas e idealização abstrata dos humanos considerou todos os humanos iguais em essência (idealmente), portadores dos mesmos valores e princípios desde o nascimento (universalização da ideia inatista), e, portanto, as mesmas garantias jurídicas devem ser aplicadas. Assim, todos são iguais em direitos inalienáveis. 
Os direitos, todavia, não são inatos. A satisfação das necessidades não é automática em razão da existência de direitos abstratos, visto que a linguagem normativa é sempre deôntica: trata-se de um ideal a atingir. Além disso, nem todas as pessoas ou todos os povos necessitam dos mesmos bens materiais e imateriais (ou direitos), em razão das diversidades culturais.

Os princípios de direitos humanos não são inatos nem universais em razão da contextualidade e temporalidade de cada ser humano: os valores e as necessidades materiais e imateriais de cada pessoa, grupo ou povo. Para além do universalismo culturalista da visão ocidental dos bens necessários à garantia da dignidade humana, também devemos atentar para as necessidades de cada cultura em particular. As análises teóricas e práticas sociais que busquem a efetivação da vida digna não podem ignorar as diferenças culturais. Pelo contrário, as teorias e práticas devem estar em consonância com a imanência do mundo. Trata-se de um compromisso ético que deve ser assumido na pesquisa, teorização e prática da defesa da vida e da dignidade.

Nesse sentido, importa a reinvenção dos direitos humanos, promovida pelo teórico espanhol Joaquín Herrera Flores, de perceber os direitos em uma constante mobilidade e transformação, ou seja, como um construído contextual. São eles os processos de luta pelo acesso igualitário aos bens materiais e imateriais a uma vida digna de ser vivida, sejam eles de expressão, convicção religiosa, educação, moradia, trabalho, meio ambiente, cidadania, alimentação sadia, lazer, formação, patrimônio histórico, cultural, etc. Então, os direitos humanos, enquanto processos provisórios de lutas, são sempre o resultado transitório pela vida digna.

Consideramos, assim, que os princípios de direitos humanos não são inatos ou universais, enquanto valores compartilhados, mas devem ser entendidos contextualmente, de modo a garantir a dignidade imanente e a satisfação das necessidades. Em última instância, significa que o maior 
valor axiológico deve ser a própria dignidade humana, na conjunção vida digna, liberdade individual e social, assim como igualdade formal e material.

\section{REFERÊNCIAS}

ALDUNATE, José (Org.). Direitos humanos, direitos dos pobres. Série V. Desafios da vida na sociedade. São Paulo: Vozes, 1991.

ANDERY, Maria Amália Pie Abib; MICHELETTO, Nilza; SÉRIO, Tereza Maria de Azevedo Pires. A experiência e o hábito como fonte das idéias, as idéias como fonte do conhecimento: John Locke. In: ANDERY et al. Para compreender a ciência: uma perspectiva histórica. Rio de Janeiro: Garamond, 2007. p. 311-327.

ARRUDA JÚNIOR, Edmundo Lima de; GONÇALVES, Marcus Fabiano. Direito: ordem e desordem, eficácia dos direitos humanos e globalização. Florianópolis: IDA, 2004.

DESCARTES, René. Os pensadores. Meditações. São Paulo: Nova Cultural, 2000 .

. Discurso del método. Buenos Aires: Centro Editor de Cultura, 2006.

DUSSEL, Enrique. Filosofía de la liberación. México: Edicol, 1977.

FLEINER, Thomas. O que são direitos humanos? São Paulo: Editora Max Limonad, 2003.

HERRERA FLORES, Joaquín. A reinvenção dos direitos humanos. Florianópolis: Fundação Boiteux, 2009a.

Teoria crítica dos direitos humanos: os direitos humanos como produtos culturais. Tradução Luciana Caplan, Carlos Roberto Diogo Garcia, Antonio Henrique Graciano Suxberger e Jefferson Aparecido Dias. Título original: Los derechos humanos como produtos culturales: crítica del humanismo abstrato. Rio de Janeiro: Lumen Juris, 2009b. 
LOCKE, John. Segundo tratado sobre o governo civil e outros serviços: ensaio sobre a origem, os limites e os fins verdadeiros do governo civil. Tradução Madga Lopes e Marisa Lobo da Costa. 3. ed. Petrópolis: Vozes, 1994.

Ensaio acerca do entendimento humano. Tradução Anoar Aiex. São Paulo: Nova Cultural, 1999. (Coleção os pensadores).

MARTÍN-BARÓ, Ignacio. Psicología de la liberación. Espanha, Madri: Trotta, 1988.

MARX, Karl. A questão judaica. 5. ed. São Paulo: Centauro, 2000.

NAÇÕES UNIDAS. Relatório de desenvolvimento humano 2010. A verdadeira riqueza das nações: vias para o desenvolvimento humano. Disponível em: <http://hdr.undp.org/en/media/HDR_2010_PT_Complete_reprint.pdf>. Acesso em: 30 mar. 2011.

SÁNCHEZ RUBIO, David. Filosofía, derecho y liberación en América Latina. Bilbao, Espanha: Editorial Desclée de Brouwer, 1999.

SEN, Amartya. Poverty and Famines: an essay on Entitlement and Deprivation. Nova York: Oxford University Press, 1983.

TADIÉ, Aléxis. Locke. Tradução José Oscar de Almeida Marques. São Paulo: Estação Liberdade, 2005. (Figuras do saber; 10).

Recebido em: 25/9/2012

Aprovado em: 2/10/2012 